\title{
EFFECTIVENESS OF POSTURAL DRAINAGE ALONG WITH DEEP BREATHING TO IMPROVE RESPIRATORY PARAMETERS AMONG THE CHILDREN
}

\author{
Mrs. C Annapurna Reddy*| Dr. Bimla Rani** \\ * Research Scholar, Himalayan University, Itanagar, Arunachal Pradesh, India. \\ ${ }^{* *}$ Research Supervisor, Himalayan University, Itanagar in Arunachal Pradesh, India. \\ DOI: http://doi.org/10.47211/trr.2021.v07i02.006
}

\begin{abstract}
Background and objectives: An Experimental Study was carried out on effectiveness of postural drainage along with deep breathing to improve respiratory parameters among the children (age 6-12 years) affected with lower respiratory tract infections admitted in pediatric ward, S.V.S Hospital, Mahabubnagar, Telangana."

Objectives of the study is To assess the respiratory parameters before giving postural drainage along with deep breathing in experimental group and control group and after giving postural drainage along with deep breathing in experimental group among children (age 6 to 12 years) affected with lower respiratory tract infection. To compare the respiratory parameters among the children (age 6 to 12 yrs) affected with lower respiratory tract infection in experimental group and control group before and after giving postural drainage along with deep breathing. To determine the association between effects of postural drainage along with deep breathing among children (age 6 to 12 years) affected with lower respiratory tract infection with their selected demographic variables. Materials and Methodology: The research design selected for the study was pre-experimental design. More specifically, one group pre-test, post test design was used in which only one group was observed before and after the independent variable was introduced. In this design the total sample was taken as one group and pre-test was administered. After the pretest, irrespective of the pre-test results, the Investigator administered Postural drainage along with deep breathing. The effectiveness of independent variable on dependent variable was tested with the help of posttest. In the present study the sample were 40 children with lower respiratory tract infection admitted in pediatric ward with convenient sampling method. Results: The collected data was analyzed by using both descriptive and inferential statistics such as frequency and percentage distribution, Mean, standard deviation, paired' test and chi square test at 0.01 level of significance with $29 \mathrm{df}$. The estimated paired 't'value was 3.55* which is significant at $p<0.001$ It shows that postural drainage along with deep breathing was effective in the rate of improving the level of respiratory parameters. Hence research hypothesis $\mathrm{H} 2$ was accepted. Conclusion: The study has showed that there was an overall improvement in the respiratory distress level among children after implementation of postural drainage along with deep breathing in children's (6-12 years) with lower respiratory infections.
\end{abstract}

Key words: deep breathing exercises, postural drainage, lower respiratory infections.

ABOUT AUTHORS:

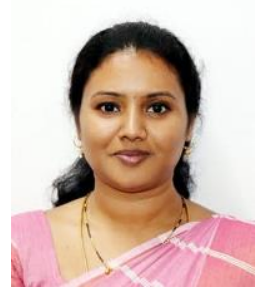

Author Mrs. C Annapurna Reddy is a Research Scholar at Himalayan University, Itanagar in Arunachal Pradesh, India.

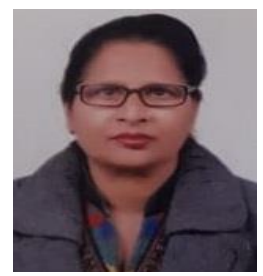

Author Dr. Bimla Rani is a Research Supervisor at Himalayan University in Itanagar, Arunachal Pradesh, India. She has presented papers in various conferences and also has many publications to her name. 


\section{INTRODUCTION}

Respiratory system is a frequent site of illness in children, respiratory infections and allergies together are responsible for many disruptions in family life and missed from school work. However the most respiratory conditions are more stressful for the children than the adult. In respiratory tract lower respiratory infection is one of the leading common infections occurring in childhood.

\section{NEED FOR THE STUDY}

In Globally Lower respiratory tract infections among children place a considerable strain and serious on the health budget. In 2014 lower respiratory tract infection was still the leading cause of deaths among all infectious diseases, and they accounted for 3.9 million deaths worldwide. ${ }^{13}$

According to WHO World incidence of lower respiratory tract infection in the children age group of 6 to 12 years estimate that $12 \%$ in U.S, $43 \%$ in Canada, $10 \%$ in Bangladesh and Pakistan, $6 \%$ in Nigeria, Indonesia and China, $17 \%$ in North Sweden, $14 \%$ in Australia, and with highest estimation of rates in India is $64.2 \% .{ }^{14}$

As for national surveys in India it is estimated that 3.6\% in Chandigarh, $18 \%$ in Tamilnadu, $2.3 \%$ in Simla, $19 \%$ in Chennai, $16 \%$ in Delhi, $4 \%$ UttarPradesh, $2.1 \%$ in Kerala, $4 \%$ in Madhya Pradesh and $63.2 \%$ in Telangana. ${ }^{15}$

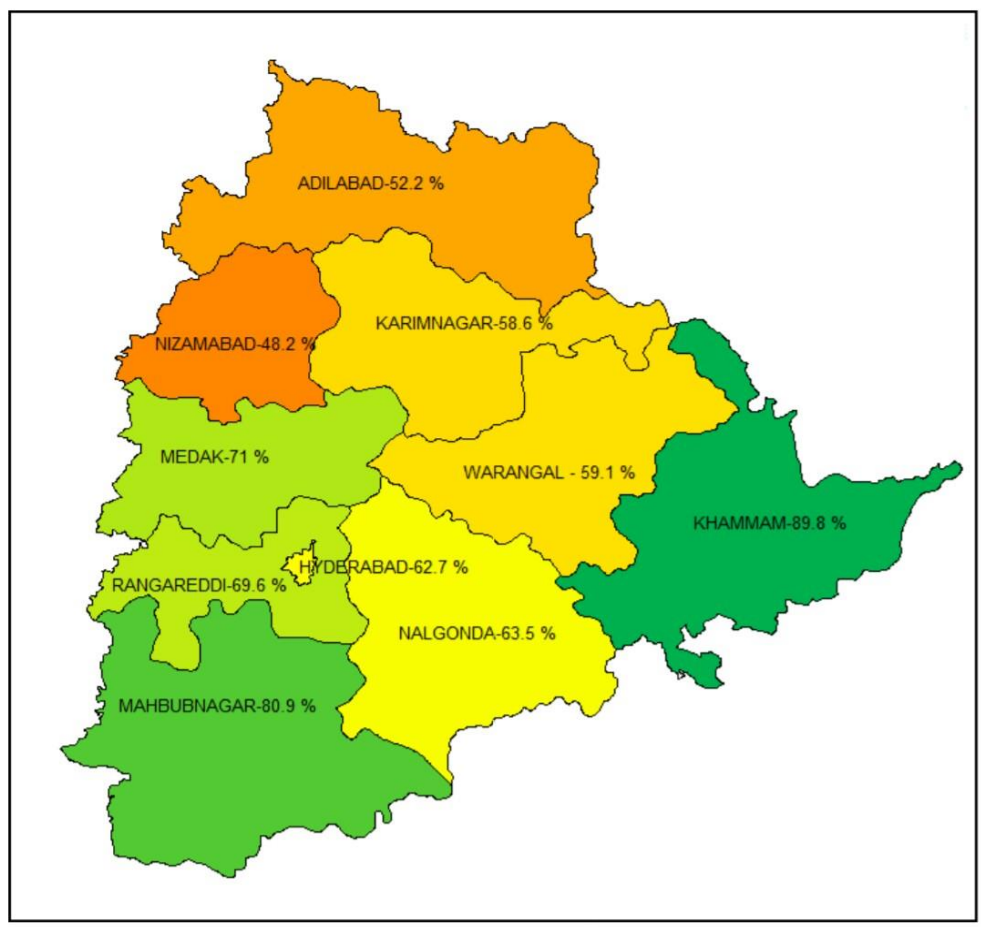

Fig. no- 0.1 Telangana state incidence rate of ARI in children

In the state of Telangana has, high incidence about LRTI in children on districts Khammam (89.8\%) and Mahbubnagar (80.9\%), the districts Medak (71\%), Rangareddy(69\%), Nalgonda(63\%) and Karimnagar(58\%) have medium incident rate in ARI, the districts Nizamabad (48.2\%) and Adilabad (52.5\%) have low incidence levels. The state capital, Hyderabad has suboptimal awareness levels (62.7\%). ${ }^{16}$

In Mahabubnagar at S.V.S hospital every day 40 cases are been visited to OP department, out of which 8-10 cases has been admitted in S.V.S Hospital with of Lower Respiratory Tract Infection. ${ }^{16}$

A comparative study was conducted on Lower respiratory tract infection among 400 children's by using randomized sampling technique the data was collected based on the signs and symptoms of ARI at Gulbarga on 16 May 2017. The objectives of the study is to assess the morbidity pattern among children. The study reveals that out of the $400 \mathrm{ARI}$ was detected among the 109 children giving an incidence of $17 \%$ URTI was found and $29 \%$ with LRTI. The researcher concluded that community education program should focus on addressing specific issues of Lower respiratory tract infection 


\section{PROBLEM STATEMENT:}

An Experimental Study was carried out on effectiveness of postural drainage along with deep breathing to improve respiratory parameters among the children (age 6-12 years) affected with lower respiratory tract infections admitted in pediatric ward, S.V.S Hospital, Mahabubnagar, Telangana."

\section{OBJECTIVES OF THE STUDY}

1. To assess the respiratory parameters before giving postural drainage along with deep breathing in experimental group and control group and after giving postural drainage along with deep breathing in experimental group among children (age 6 to 12 years) affected with lower respiratory tract infection.

2. To compare the respiratory parameters among the children (age 6 to $12 \mathrm{yrs}$ ) affected with lower respiratory tract infection in experimental group and control group before and after giving postural drainage along with deep breathing.

3. To determine the association between effects of postural drainage along with deep breathing among children (age 6 to 12 years) affected with lower respiratory tract infection with their selected demographic variables.

\section{HYPOTHESIS}

$\mathbf{H}_{1}$ : there will be significant difference between the pretest and post test level of respiratory parameters among children with lower respiratory infections in experimental group

$\mathbf{H}_{\mathbf{2}}$ : There will be significant difference between the pretest and post test level of respiratory parameters among children with lower respiratory tract infections in experimental group and control group.

$\mathbf{H}_{3}$ : there will be significant association between pretest and post test level of postural drainage along with deep breathing on significant respiratory parameters with their selected demographic variables between experimental group and control group.

\section{METHODOLOGY}

The research design selected for the study was pre-experimental design. More specifically, one group pre-test, post test design was used in which only one group was observed before and after the independent variable was introduced. In this design the total sample was taken as one group and pre-test was administered. After the pretest, irrespective of the pre-test results, the Investigator administered Postural drainage along with deep breathing. The effectiveness of independent variable on dependent variable was tested with the help of post-test. In the present study the sample were 40 children with lower respiratory tract infection admitted in pediatric ward at S.V.S hospital, Mahabubnagar, Telangana. The children (6-12yrs) were selected by using the sample size consists of 40 children those who had been diagnosed with lower respiratory tract infection. Among those, 20 participants were selected for experimental group and 20 for control group.

A pilot study was conducted from 15/05/20 to 25/05/20 in P.I.C.U Ward, SVS Hospital, Mahabubnagar, Telangana, after obtaining formal permission from Residential Director, SVS Hospital, to assess the feasibility and reliability of the tool. The obtained value of Karl Pearson correlation of coefficient was $r=0.99$, which infers the tool as reliable. The main study was conducted in paediatric ward of SVS Hospital Mahabubnagar,Telangana from 02/06/20 to $30 / 06 / 20$.

The collected data was analyzed by using both descriptive and inferential statistics such as frequency and percentage distribution, Mean, standard deviation, paired' test and chi square test at 0.01 level of significance with $29 \mathrm{df}$.

\section{RESULTS}

Findings of the study were discussed under section - A, B, C.

Section-A: includes demographic findings in experimental group 8(40\%) of them belonged to the age group of 6-8 years and $9(45 \%)$ belongs to $8-10$ years, and $3(15 \%)$ belongs to $10-12$ years. $14(70 \%)$ were female children and $6(30 \%)$ were male children. Regarding weight $16(80 \%)$ with below normal, and $4(20 \%)$ with normal weight, and $0(0 \%)$ with above normal. 9(45\%) were first, and $8(40 \%)$ second child, and $3(15 \%)$ were third child. Regarding immunization status $18(90 \%)$ up to date, and $1(5 \%)$ with post dated $1(5 \%)$ with irregular, and $0(0 \%)$ with delayed due to illness. Regarding residence 5 (25\%) were from village and 15 (75\%) were from sub urban areas. Regarding monthly income 2(10\%) withRs.7100/-. Regarding Previous episode of respiratory infection 1(5\%) with first episode, and 15(75\%) with 2-3 episodes, and 2(10\%) with 4-5 episodes, and 2(10\%) with>5 episodes. Regarding frequency of hospitalization $1(5 \%)$ with first time, and $15(75 \%)$ with 2-3 times, and 2(10\%) with 4-5 times, and $2(10 \%)$ with $>5$ times. Regarding number of days hospitalization $1(5 \%)$ with 7 days. Regarding indirect smoking atmosphere in house $7(35 \%)$ with yes, and $13(65 \%)$ with no. 


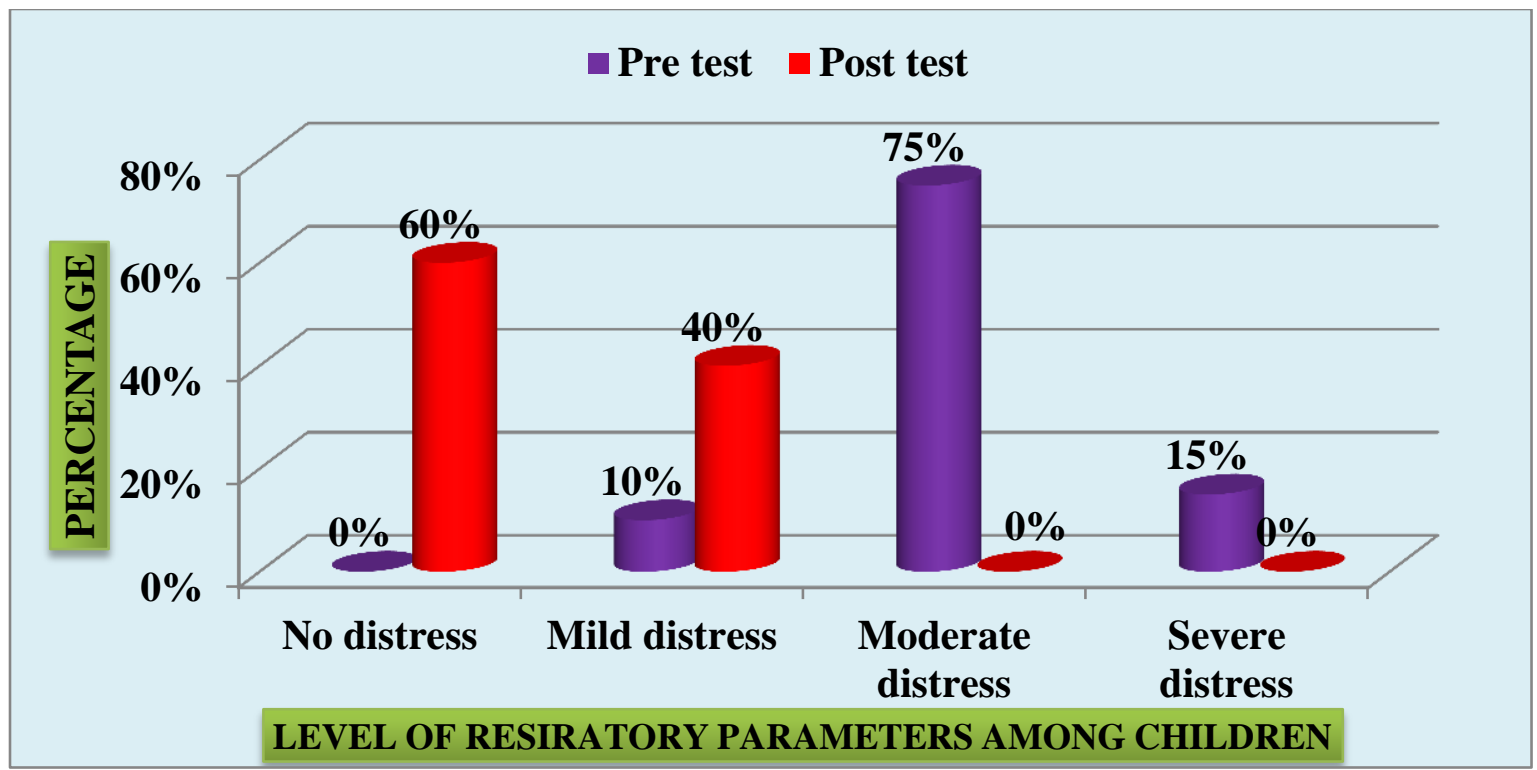

Section-B In control group 9(45\%) of them belonged to the age group of $6-8$ years and $8(40 \%)$ belongs to $8-10$ years, and $3(15 \%)$ belongs to $10-12$ years. $10(50 \%)$ were female children and $10(50 \%)$ were male children. Regarding weight $11(55 \%)$ with below normal, and $9(45 \%)$ with normal weight, and 0(0\%) with above normal. $6(30 \%)$ were first, and $11(55 \%)$ second child, and $3(15 \%)$ were third child. Regarding immunization status $16(80 \%)$ up to date, and $2(10 \%)$ with post dated $2(10 \%)$ with irregular, and $0(0 \%)$ with delayed due to illness. Regarding residence $6(30 \%)$ were from village and 14 (70\%) were from sub urban areas. Regarding monthly income 1 (5\%) withRs.7100/-. Regarding Previous episode of respiratory infection 0(0\%) with first episode, and 15(75\%) with 2-3 episodes, and $4(20 \%)$ with $4-5$ episodes, and $1(5 \%)$ with $>5$ episodes. Regarding frequency of hospitalization $0(0 \%)$ with first time, and $15(75 \%)$ with $2-3$ times, and $4(20 \%)$ with $4-5$ times, and $1(5 \%)$ with $>5$ times. Regarding number of days hospitalization $3(15 \%)$ with 7 days. Regarding indirect smoking atmosphere in house $8(40 \%)$ with yes, and $12(60 \%)$ with no.

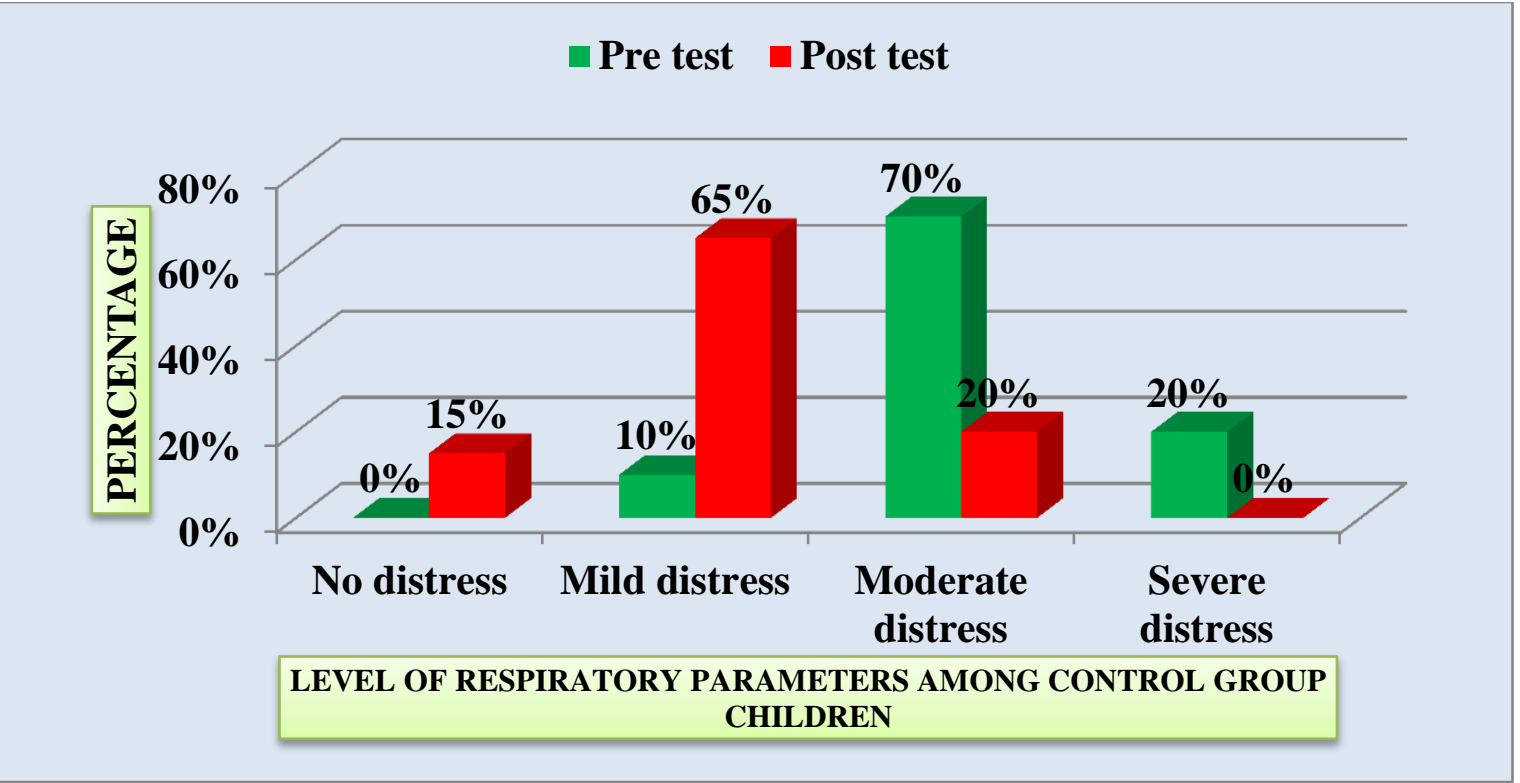

Section-C: During pre-test in experimental group, 3 (15\%) were with severe respiratory distress, 15 (75\%) had moderate respiratory distress and $2(10 \%)$ had mild distress and none of them had no distress. In control group 4 (20\%) were with severe respiratory distress, 14 (70\%) had moderate respiratory distress and 2(10\%) with mild 
distress, and none of them had no distress. During post-test in experimental group, 12 (60\%) had no respiratory distress, $8(40 \%)$ were with mild respiratory distress, 2 (10\%) were none of them had moderate and severe respiratory distress. In control group, 4 (20\%) were with moderate respiratory distress, 13 (65\%) were with mild distress $3(15 \%)$ no distress severe respiratory distress, 1 (5\%) were with none of them had severe respiratory distress The mean score on level of respiratory parameters in experimental group was 2.1.5 in post-test and 4. 95 in control group post-test. The estimated paired ' $t$ 'value was $3.55^{*}$ which is significant at $p<0.001$.

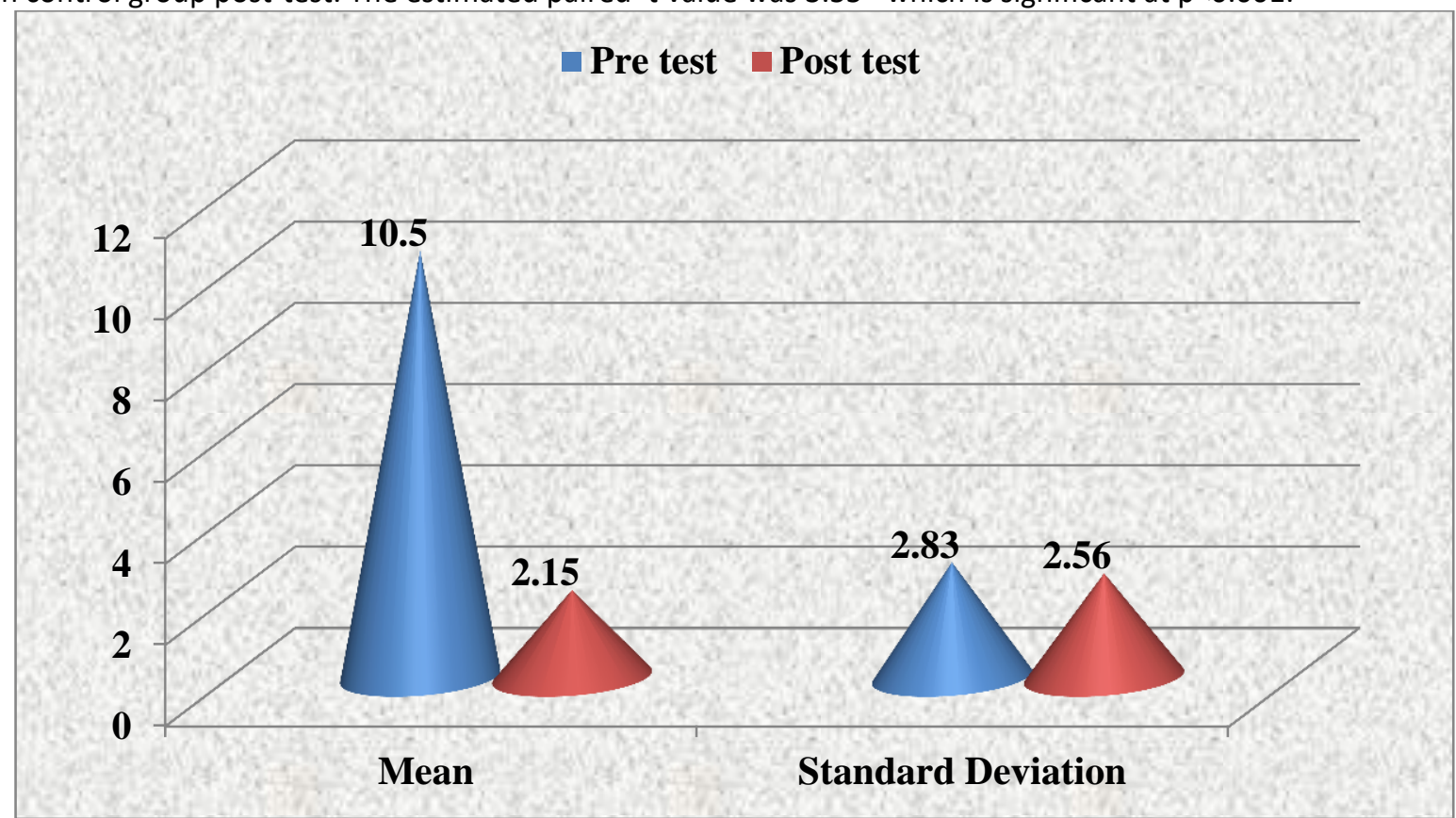

It shows that postural drainage along with deep breathing was effective in the rate of improving the level of respiratory parameters. Hence research hypothesis $\mathrm{H} 2$ was accepted. There was no significant association $(p<0.001)$ between the level of respiratory parameters among children with their selected demographic variables between the experimental group and control group. Hence, hypothesis $\mathrm{H} 3$ was not accepted

\section{RECOMMENDATIONS}

- A similar study can be conducted in different settings with different age groups with reparatory infections

- A similar study can be conducted by other techniques of clearing secretions like breathing exercises with large samples

- A descriptive study can be conducted to identify the factors that influence the respiratory status after postural drainage along with deep breathing can be undertaken

- A comparative study can be conducted on postural drainage along with deep breathing and spirometry, balloon blowing, candle blowing methods.

\section{INTERPRETATION AND CONCLUSION}

The study has showed that there was an overall improvement in the respiratory distress level among children after implementation of postural drainage along with $v$ deep breathing in children's (6-12 years) with lower respiratory disease at S.V.S Hospital, Mahabubnagar, Telangana. 


\section{REFERENCES:}

1. Adele Pillitery, (2005). "Child health nursing”, (2 Ed.). Philladelphia; J.B.Lippincott Company Publishers. Pp 576-589.

2. Gupta .P. (2005). "Statistical Methods", 23rd (Ed). New Delhi, Sultan Chand and Sons Publications

3. Basavanthappa, B.T. (2006). "Pediatric/child health nursing", (1st Ed.). New Delhi: Abuja publishing house. Pp 615-632.

4. Dorothy, R.M. (2006). "Textbook of pediatric nursing", (6th Ed.). New Delhi: Elsevier Publications. Pp 947955, 611-613, 768-773.

5. Wong's, (2009). "Nursing care of infants and children", (8th Ed.). New Delhi: Elsevier publishers. Pp 783795.

6. Gupta D.C. (1994). "Introduction to Statistics", New Delhi: Jaypee Brothers Publications

7. Gupta .P. (2005). "Statistical Methods", 23rd (Ed). New Delhi, Sultan Chand and Sons Publications

8. Marriner Ann., (2002). "Nursing theories and its Work" (3rd Ed). Philadelphia: Mosby Publication. Pp 184.

9. National guidelines, (2003). "Asthma by consensus", IAP Respiratory chapter. Pp 18.

10. Margaret.G.Marks, (1967). "Introductory Paediatric nursing", (4th Ed). Philladelphia: J.B. Lippincott Company Publishers. Pp 216-220.

11. Nancy.T. Hatfield, (2005). "Introduction to Paediatric nursing", (6th Ed.). Lippincott Company Publishers. Pp 367-374.

12. Nelson, (2004). "Textbook of pediatrics", (11th Ed.). India: saunders Publishers. Pp 1180-1185.

13. Park, K. (2009). "Preventive and social medicine", (20th Ed). Jabalpur: Bhanot Publishers. Pp 142-178.

14. Parul dutta, (2007). "Paediatric nursing", (2nd Ed). New Delhi: Jaypee brothers' publishers. Pp 274-273.

15. Kozier and Erbs "Fundamentals of nursing" $\left(10^{\text {th }} \mathrm{Ed}\right)$. India educational services publication. $\mathrm{P}$ 1294-1295.

16. Polit O.F, Hungler B.P. (1999). "Nursing Research Principles and Method", (6th Ed). Philadelphia, Lippincott Publications.

17. 17 .J Clin Diagn Res. 2017 May, 10(5):LC08-LC13.Published online 2017 May 1 doi:7860/jcdr/2017/15509.7779.

18. 18. Reference SS- M Population health volume 8, August 2016, by AA Seidu 2016 cited by 4 . Related article

19. 19. Nilanjan MK. A longitudinal study on ARI among rural under-fives. Indian Journal of Community Medicine. 2015.

20. 20. .Ganesh Kumar, Anindo Majumdar, Veera Kumar, Bijay Nanda Naik, Kalaiselvi Selvaraj, andKarthik Balajee 2014 